\title{
الأمم المتحدة: من التدخل الإنساني إلى مبدأ مسؤولية الحماية
}

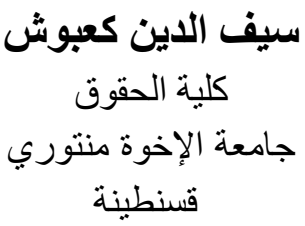

مقدّمة:

إن سعي منظمة الأمم المتحدة في تجنيب

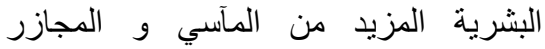

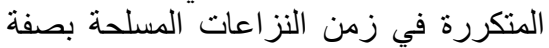

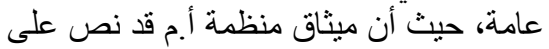

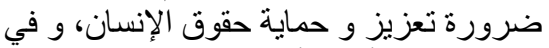
سبيل ذللك لجأت الأمم المتحدة إلى إلى استخدام

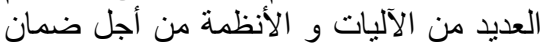

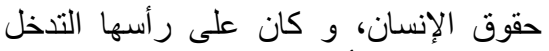

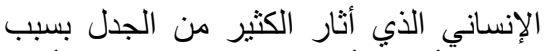

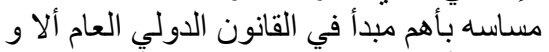

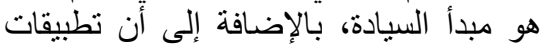

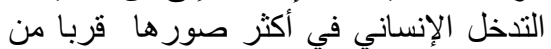

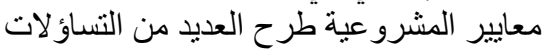

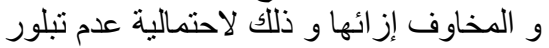

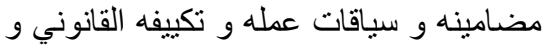
معايير ضبطه بالثكل الكافي الذي يلبي ماتي ماته

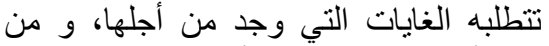
جهة أخرى فإن تدخل الأمم المتحدة الإنساني الإني لوقف الانتهاكات الجسيمة لحقوق لاخل الات لحت

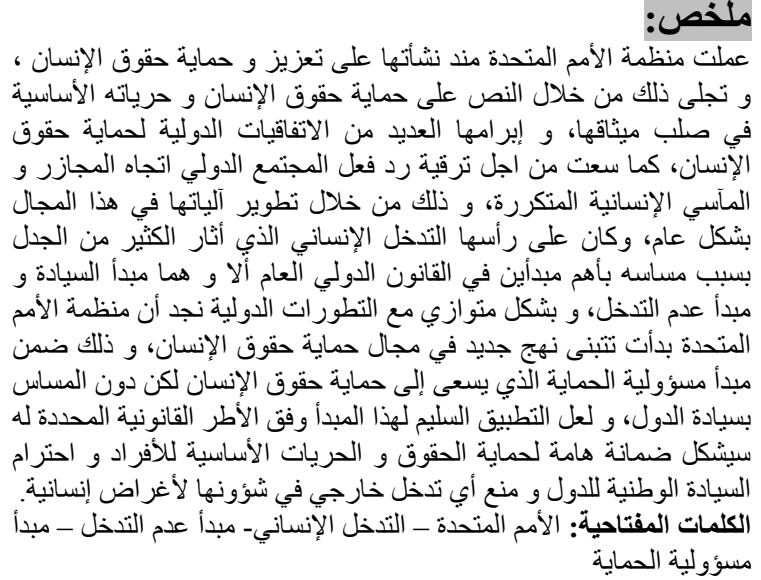

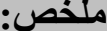

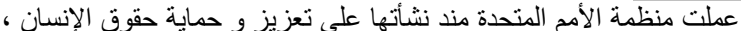

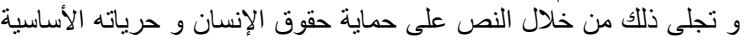

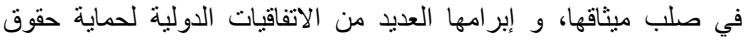

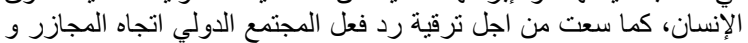

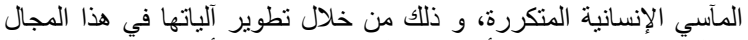

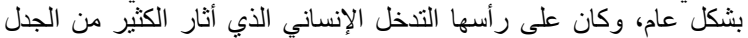

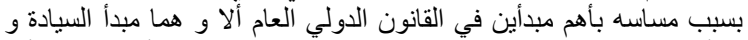

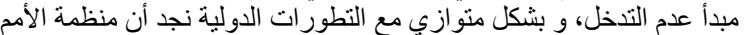

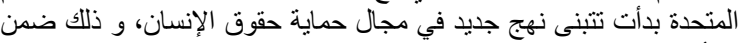

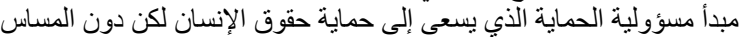

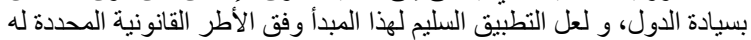

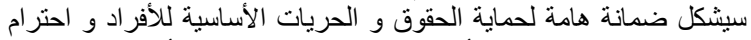

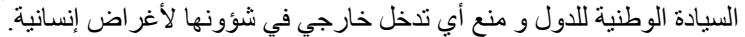
الكلمات المفتاحية: الأمم المتحدة ـ التنخل الإنساني- مبدأ عدم التنخل - مبدأ

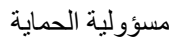

\section{Abstract:}

The United nation has worked since its establishment to promote \& protect human rights its charter this has been manifested in the protection of human rights \& fundamental freedoms at the heart of its charter, the conclusion of several international conventions for the protection of human rights and the promotion of the reaction of the international community towards Including the humanitarian intervention that has caused much debate because of the two most important principles of international public law, namely the principle of sovereignty and the principle of non-interference in parallel with International developments The United Nations It has begun to adopt a new approach to the protection of human rights within the principle of the responsibility of protection which seeks to protect human rights but without prejudice to the sovereignty of States. The proper application of this latter principle in accordance with its legal framework will constitute an important guarantee for the protection of the fundamental rights and freedoms of individuals Respect the national sovereignty of States and prevent any external interference in its affairs for humanitarian aims.

Key words: United nation - Humanitarian intervention - The principle of non-intervention - The principle of the responsibility to protect 
الإنسان يقتصر على مرحلة التدخل و ليس هناك تصور لمرحلة ما بعد التدخل الإنساني، سواء فيما

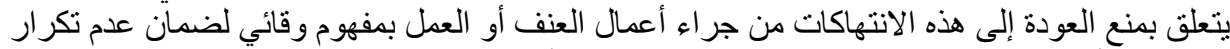

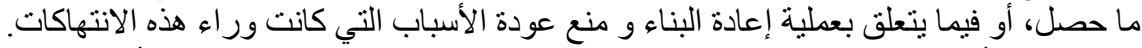

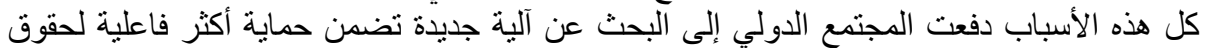

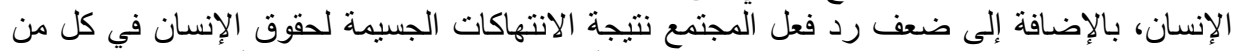

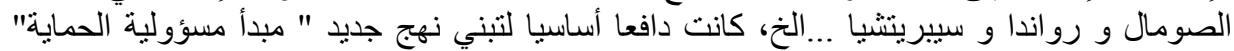

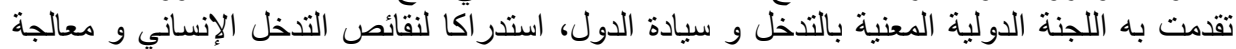

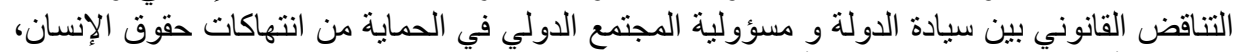

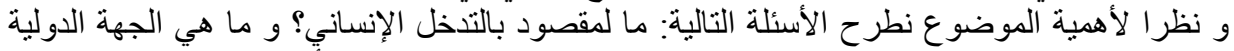

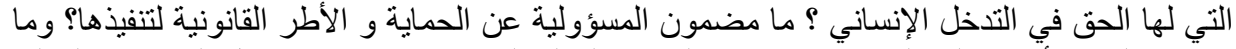
مدى فاعلية مبدأ مسؤولية الحماية في تعزيز الحماية الدولية لحقوق الإنسان من خلال التطبيقات العملية

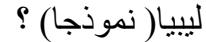
و للإجابة على هاته الأسئلة تم تقسيم الموضو عانه كالأتي: أولا: ماهية التنخل الإنساني ومدى مشرو عيته

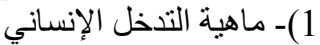
2)- مدى مشرو عية التدخل الإنساني الإني

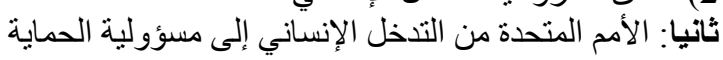

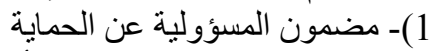
2)- تطبيق مسؤولية الحماية في الأزمة الليبية اليخية

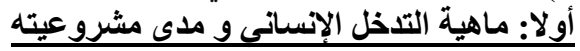

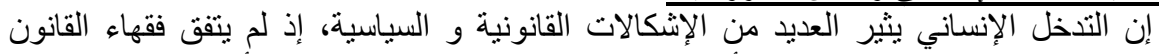

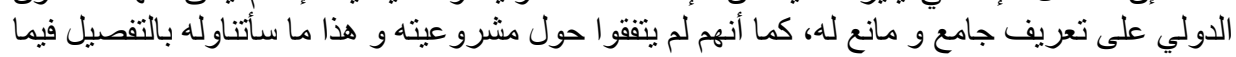

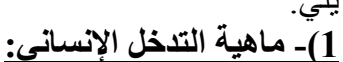

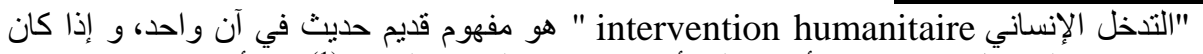

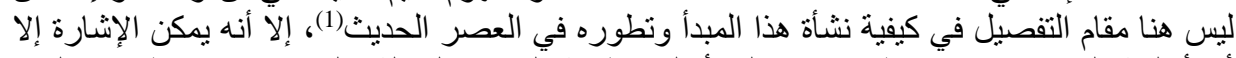

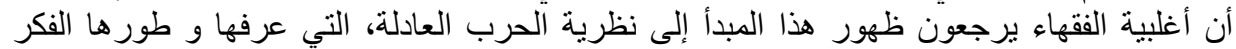

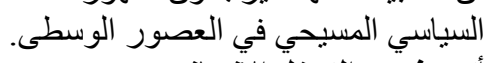
أ)- مفهوم التدخل الإنساني في التئي أختلف فقهاء القانون الدولي في تحديد مفهوم التدخل الدولي الإنساني و انقسمو إلى اتجاهين:

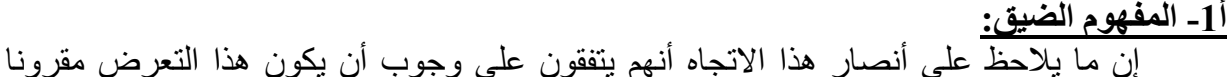

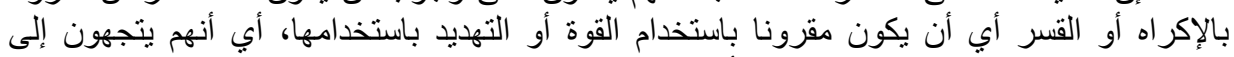

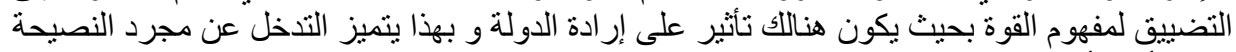
الودية أو التأثير السياسي العامة (2).

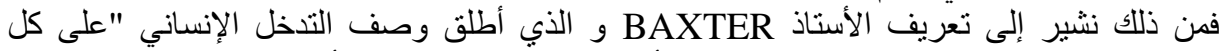

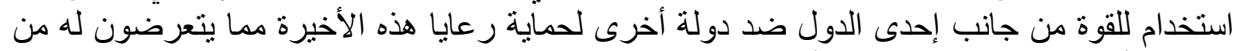

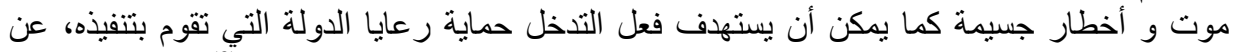

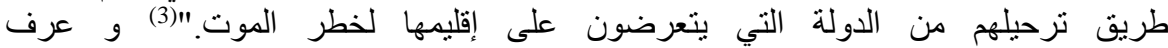

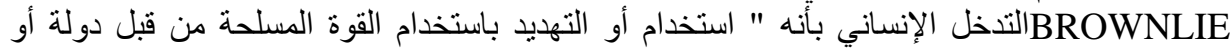
جماعة مقاتلة أو منظمة دولية بهذف حماية حقوق الإنسان."(4) بالنه 
أما THOMAS FRANK فيعرف التنخل الإنساني:" بأنه يقوم باستخدام القوة أو التهايد

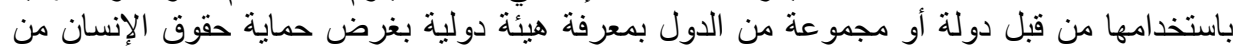

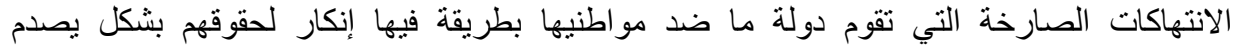

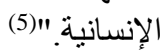

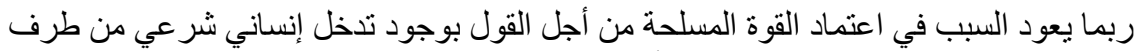

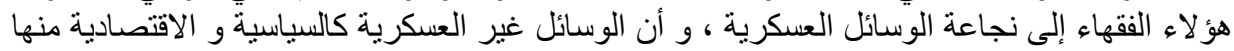

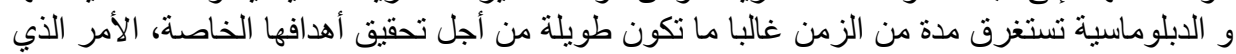

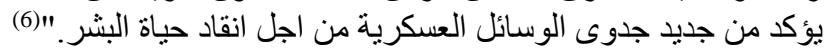

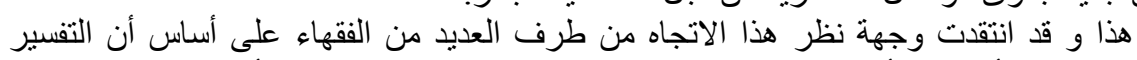

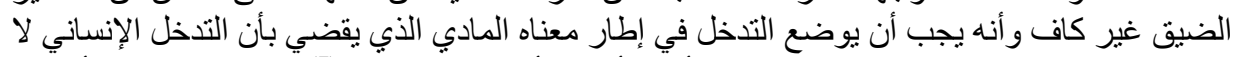

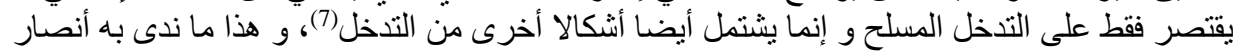
المفهوم الو اسع للتنخل لإنساني.

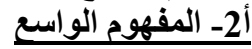

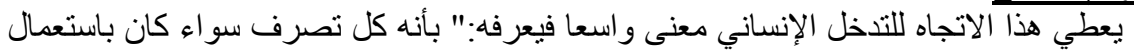

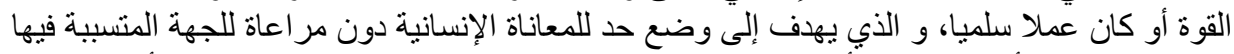

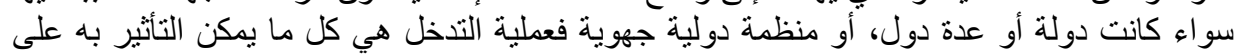

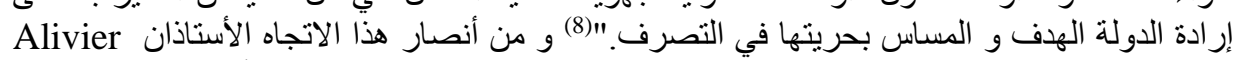
Pierre klein و corten

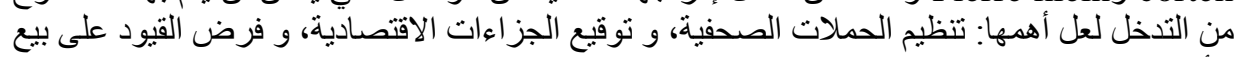

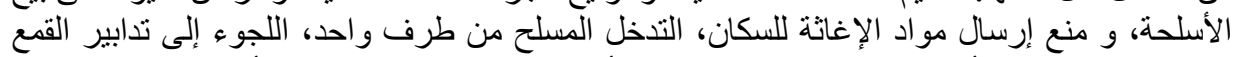

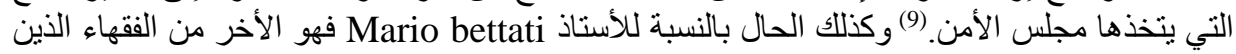

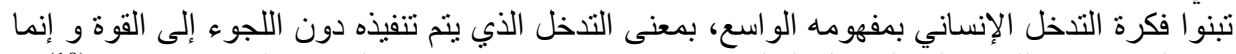

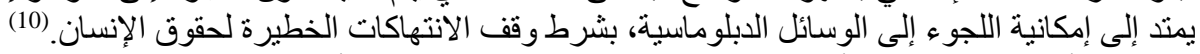

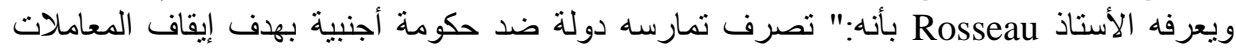

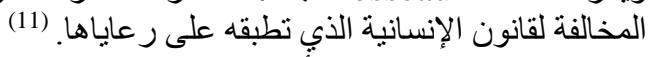

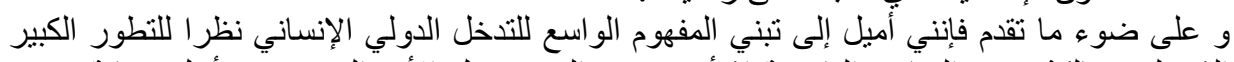

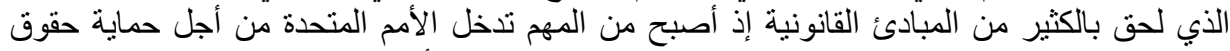

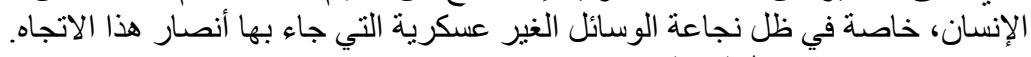

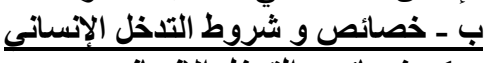

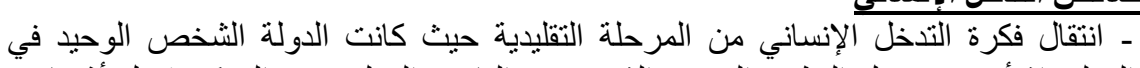

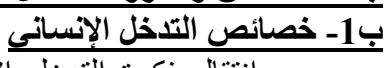

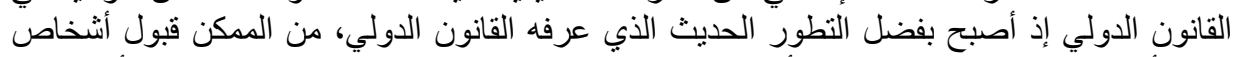

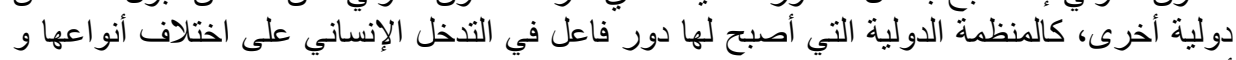

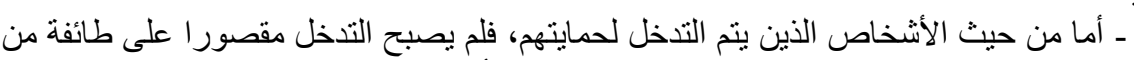

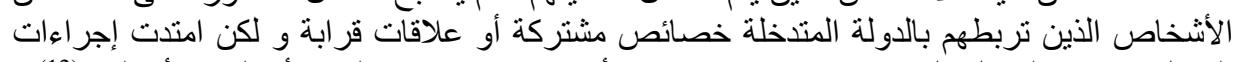

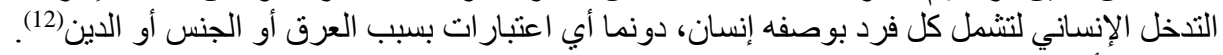

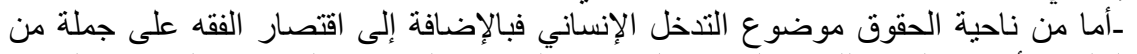

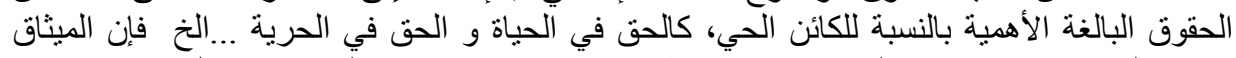

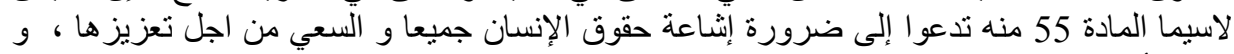
هذا ما أكده الإعلان العالمي لحقوق الإنسان الذي ارسى بدوره نظاما عالميا لحقّق الإنسان ، يمكن لكل 
فرد في ظله الحق في التمتع بكافة حقوقه و السعي من أجل تحقيق الضمانات الجدير باحترامها ، و في

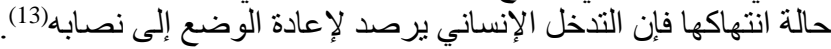

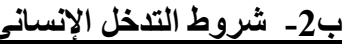

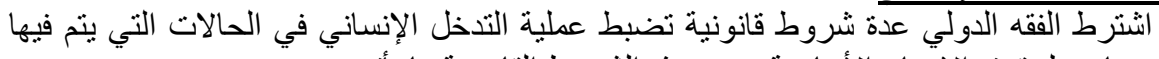

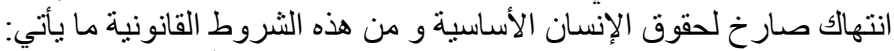

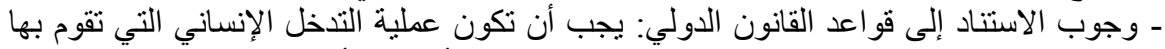

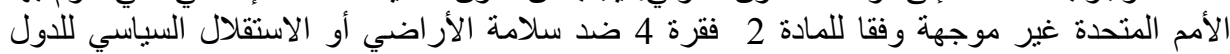

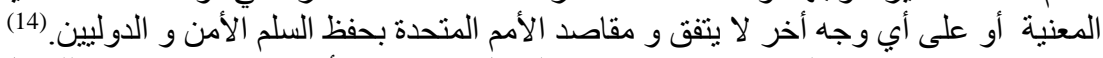

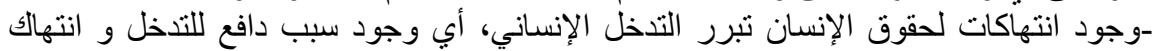

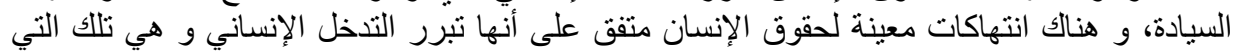

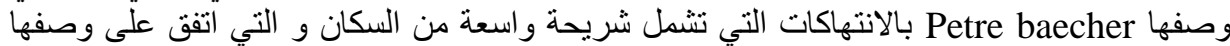

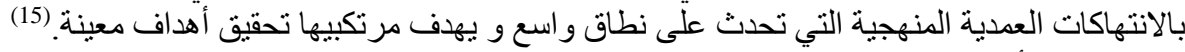

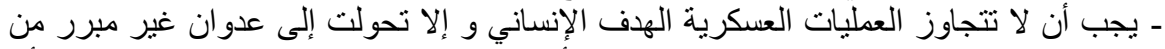

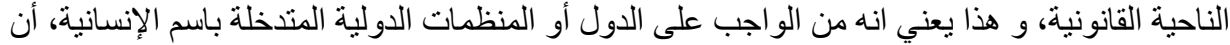

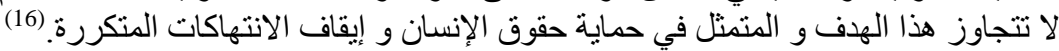

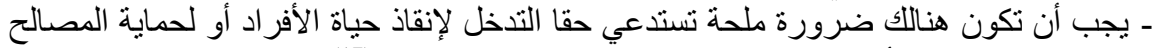

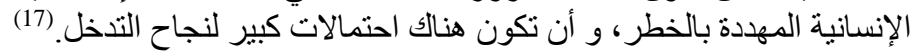

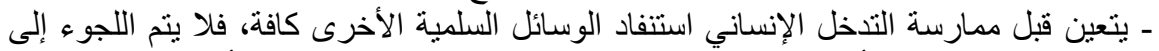

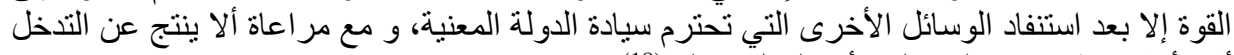
أثنار أكثر خطورة مما لو ترك الأمر ليحل داخليا.

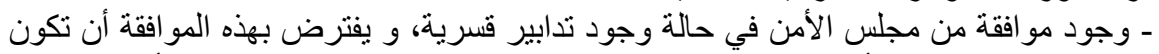

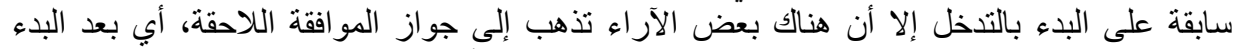
بالتدخل بشرط وجود ضرورة ملحة تبرر ذلاكل (19)، مع ضرورة الأن أن يكون قرار التدخل صحيحا و قانونيا

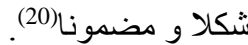

ـ كما جرى العمل على انتتراط الحكومات الثرعية لقبول التدخل الإنساني وفقا لما يقتضيه مبدأ

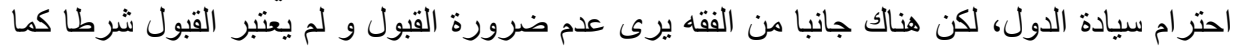

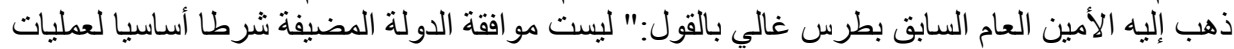
حفظ السلامهو فور صدور قرار الإمبل مجلس الأمن يملك التنخل الإنساني الأساس القانوني الكافي."(21) 20-مشروعية التتخل الإنسانى:

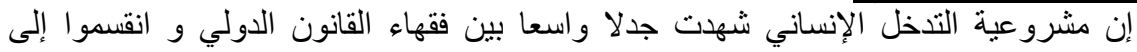
اتجاهين على غرار اختلافهم في تحديد معنى موحد و دقيق للتندخل الإنساني و هذا ما سنتنتاوله بالتفصيل فيما يلي: أــ عدم مشروعية التدخل الإنسانى خارج إطار منظمة الأمد المتحدة

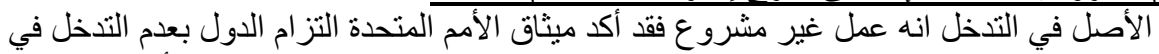

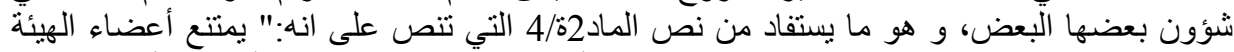

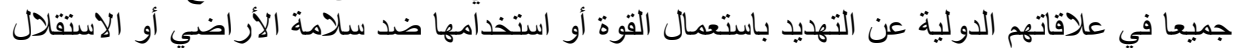

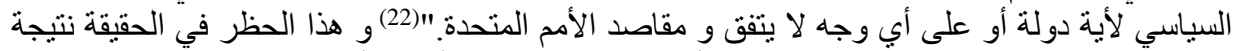

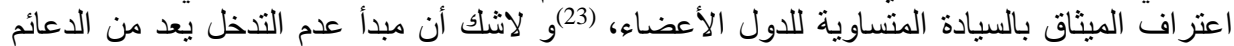

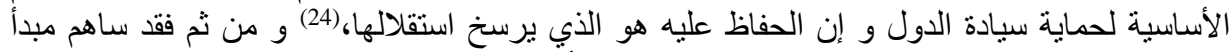

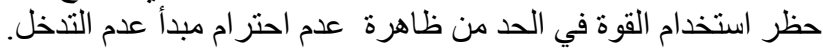

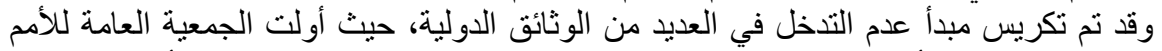

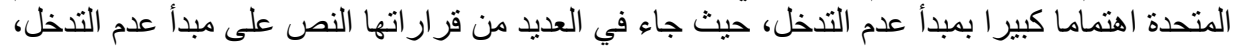




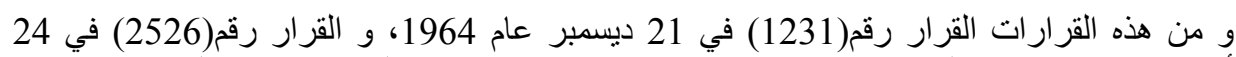

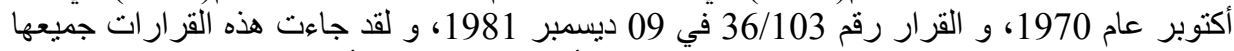

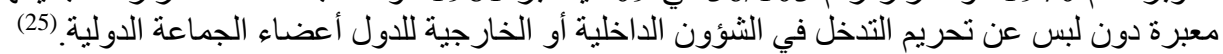

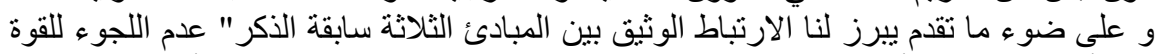

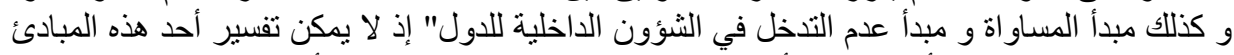

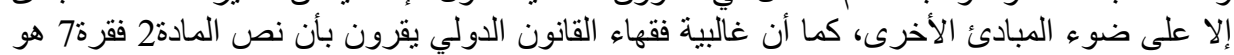

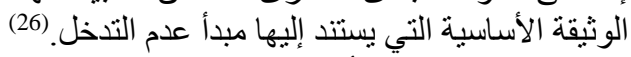

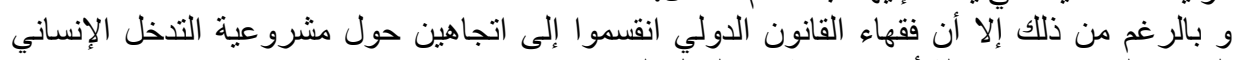
المنفرد الذي تمارسه دولة أو مجمو عة من الدول الأل إلى اتجاهين:

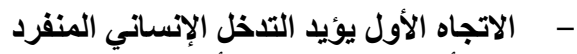

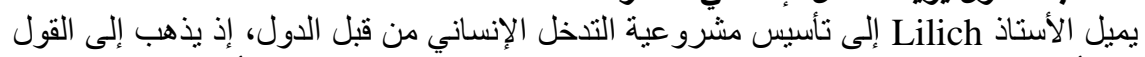

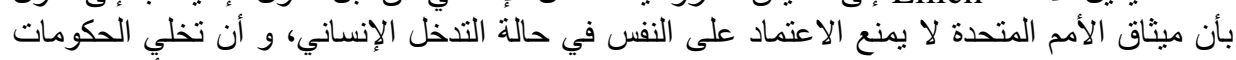

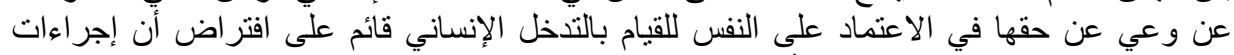

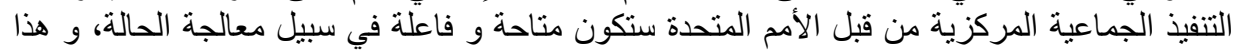

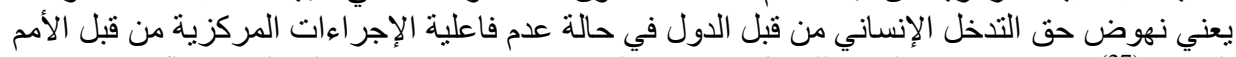

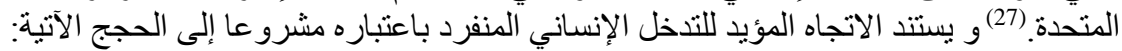

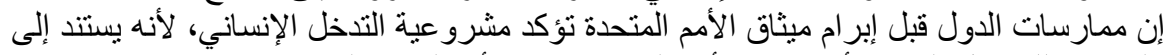

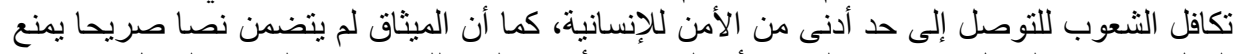

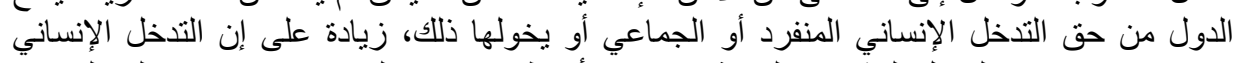

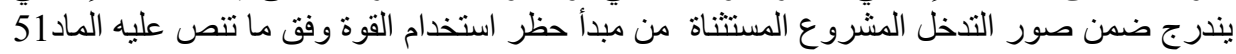

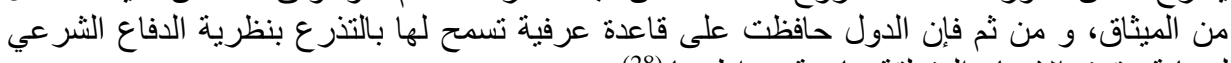

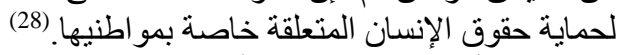

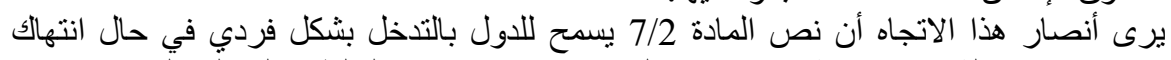

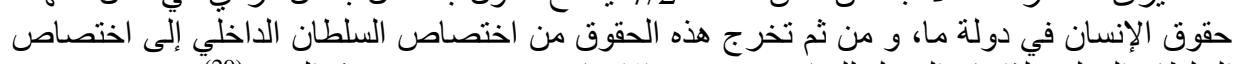

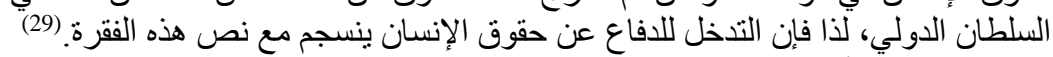

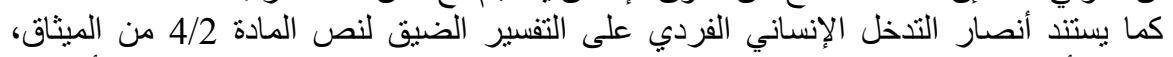

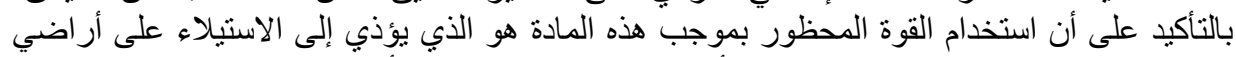

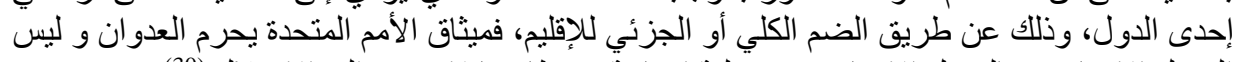

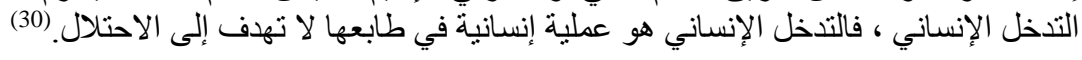

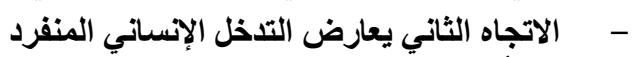

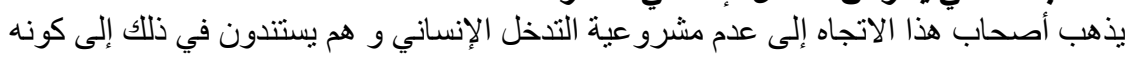

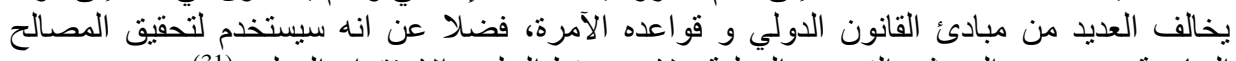

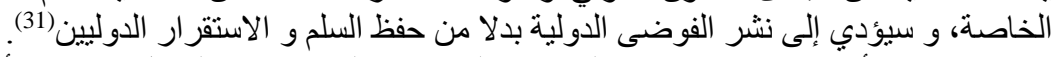

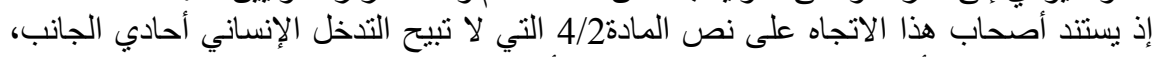

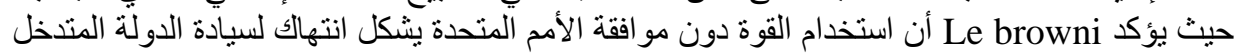

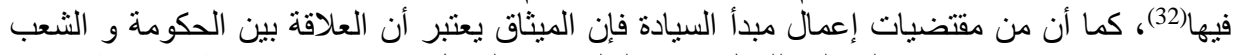

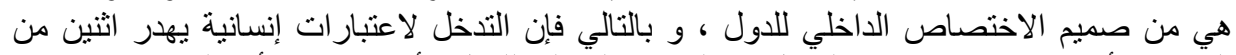

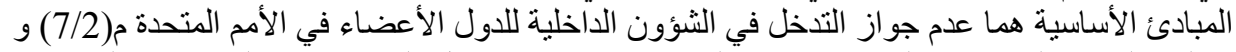

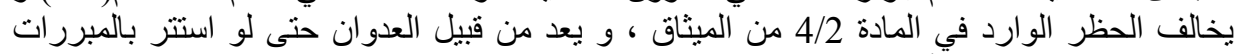

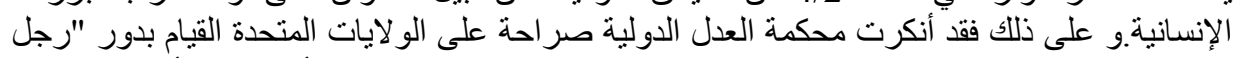
البوليس" الذي يفتش عن احتر ام القانون و حقوق الإنسان داخل حدول على الدول الأخرى كما أكدت الدحكمة 
على أن كل عمل ينتهك مبدأ سيادة الدولة مرفوض طالما أنه يمثل انغماسا في الثؤون الداخلية للدول حتى و لو ارتدى مسوغ عقل حقوق الإنسان (33).

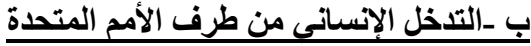

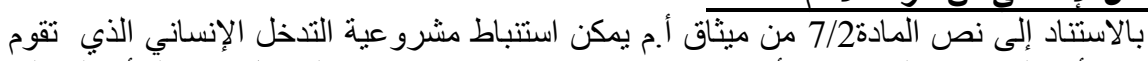

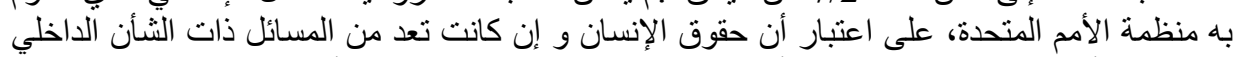

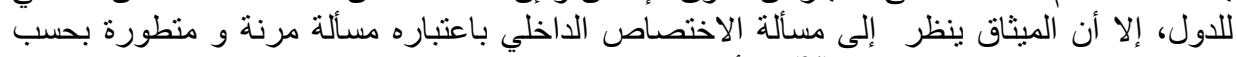

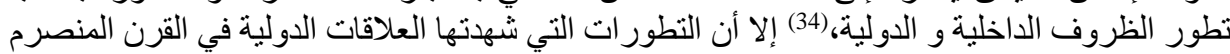

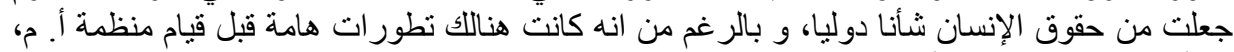

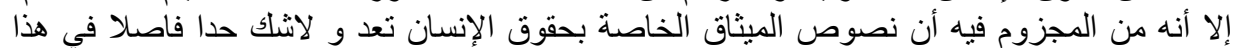

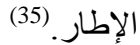

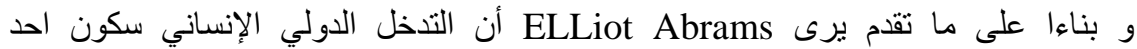

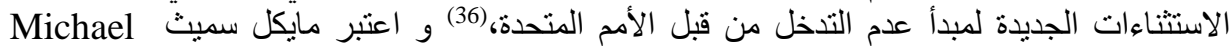

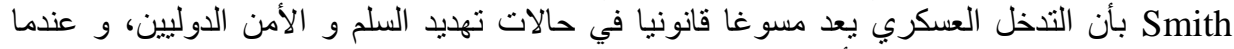

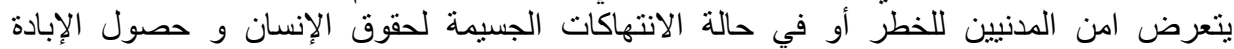

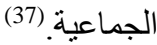
و يرى الأستاذ Reisman :"بأن التدخل الإنساني من قبل الأمم المتحدة بعنمد على الهيكل الرئبس

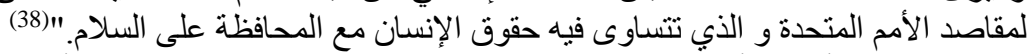

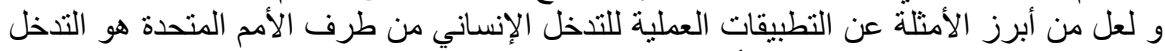

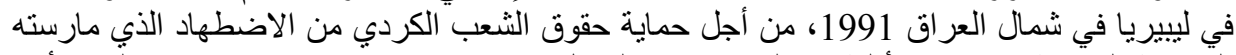

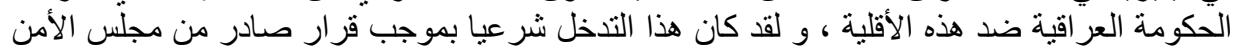

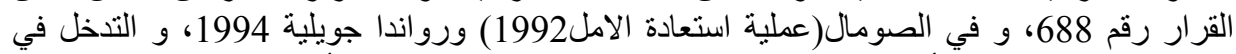
البوسنة و الهرسك في أوت 1995، كل هذه التخخلات الإنسانية كانت أنثاء نزاعات التان مسلحة غير في

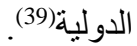

ثانيا- الأمم المتحدة من التدخل الإنسانى إلى مسؤولية الحماية

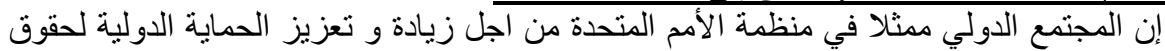

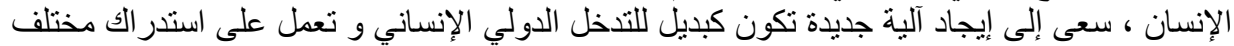

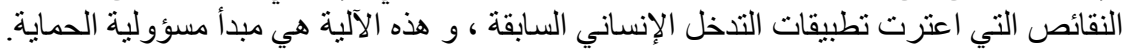

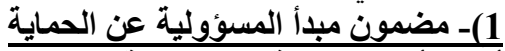

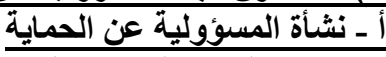

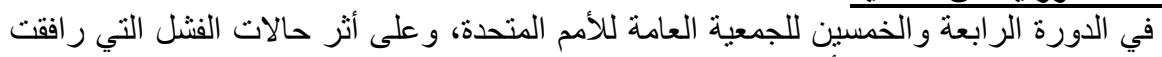

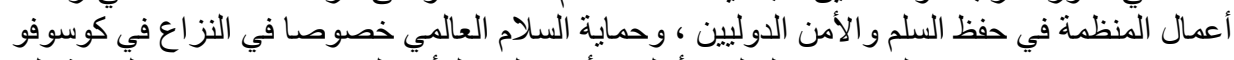

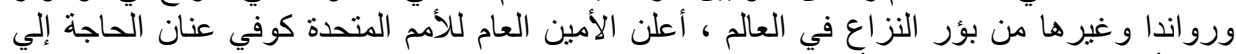

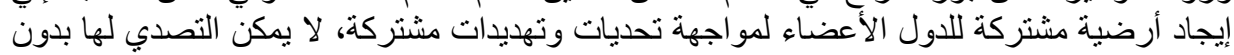

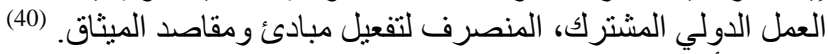

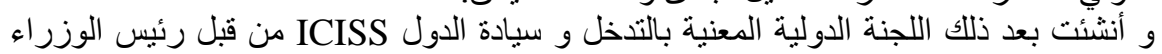

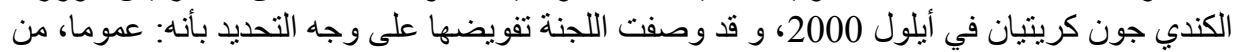

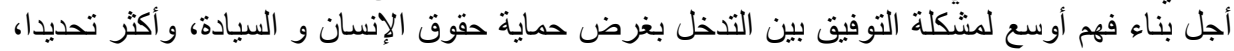

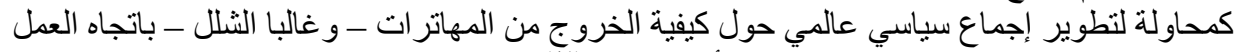

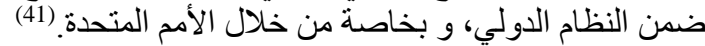

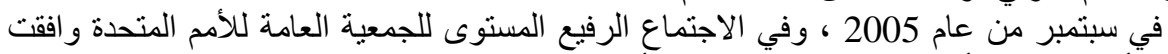

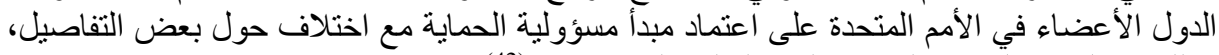

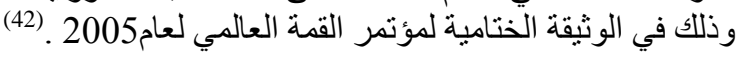


ب ـ مفهوم مسؤولية الحماية:

يقصد بمسؤولية الحماية من وجهة نظر اللجنة أن سيادة الدولة تعني المسؤولية عن حماية رعاياها

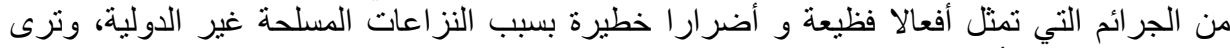

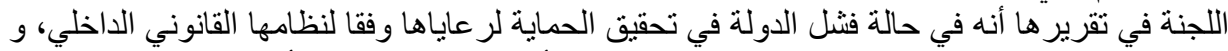

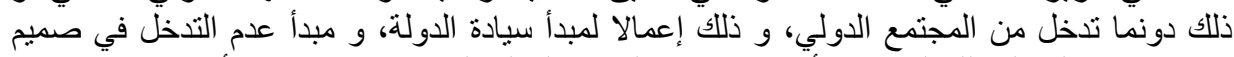

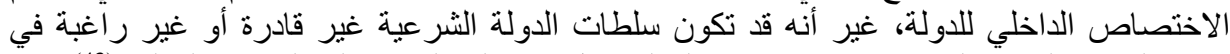

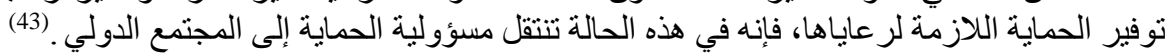

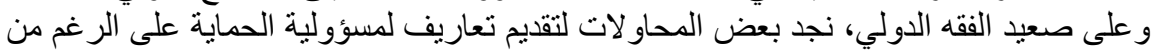

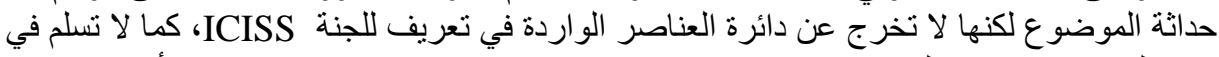

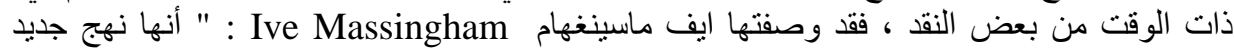

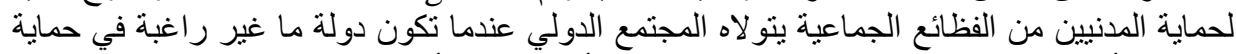

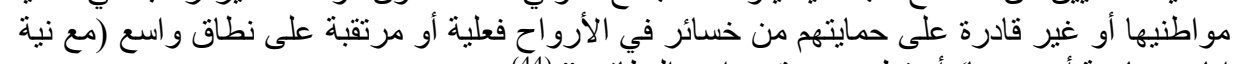

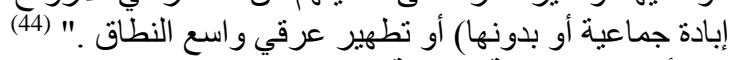
ج - أركان مسؤولية الحماية:

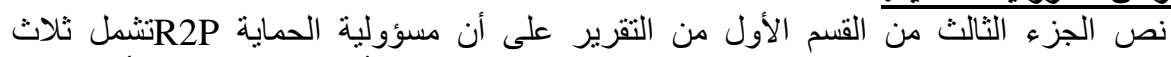

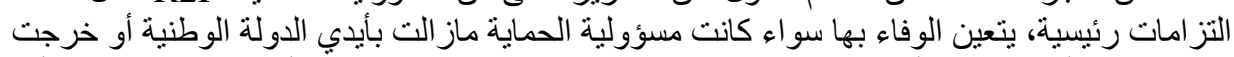

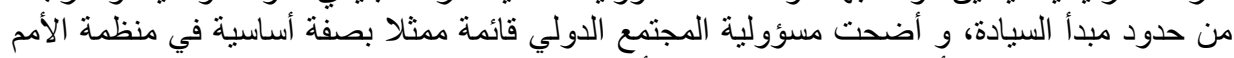

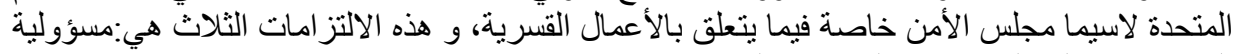
الوقاية مسؤولية الردد ، مسؤولية إعادة البناء.

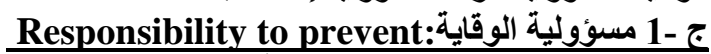

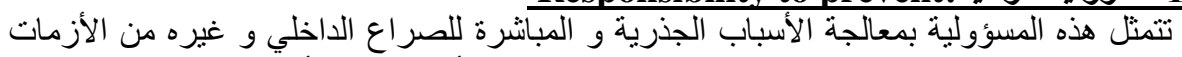

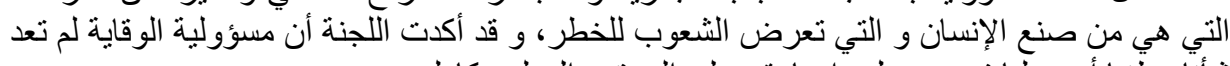

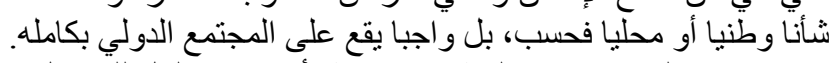

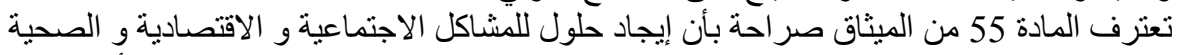

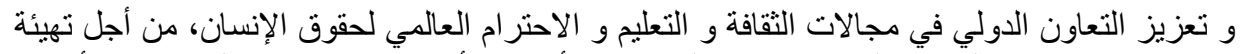

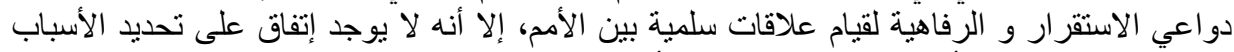

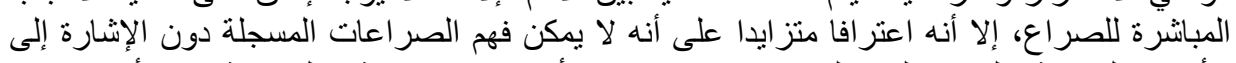

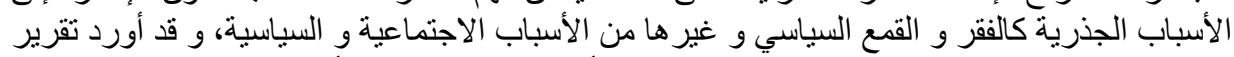

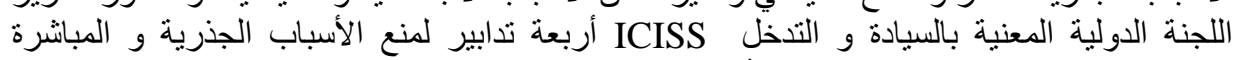

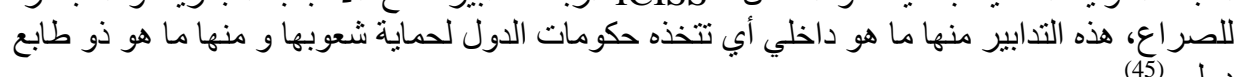
- التدابير السياسية: و تتعلق هذه التدابير بما يمكن التوصل إليه داخليا من أسس الديمقراطية و

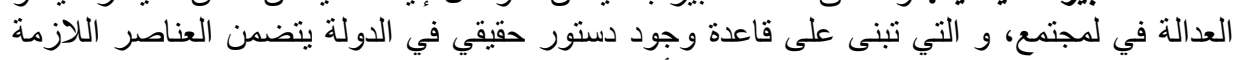

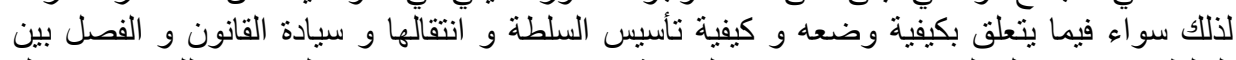

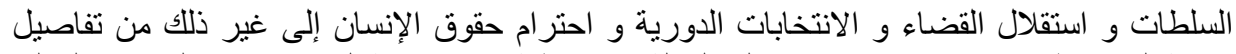

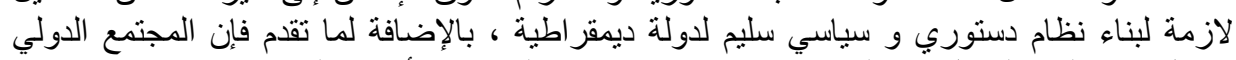

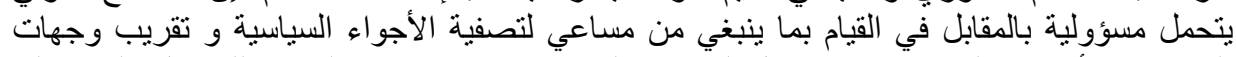

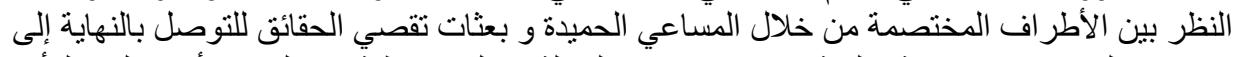

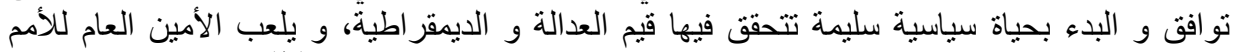

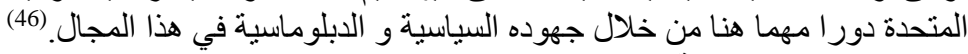

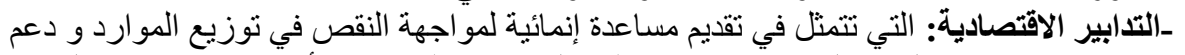

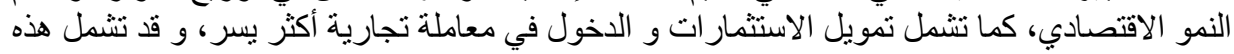


التدابير إتحاد إجراءات ذات طبيعة قصبرة كالتهايد بجزاءات تجارية و مالية، و سحب كافة أنواع

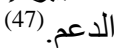

ـالتدابير القانونية: و تشمل هذه التدابير العمل على تحقيق سيادة القانون و حكم القضاء و

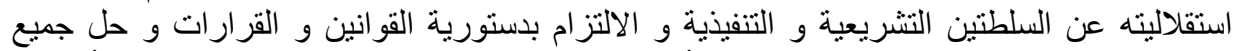

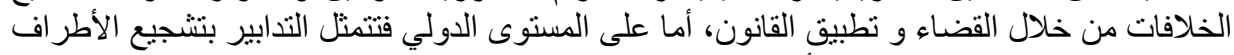

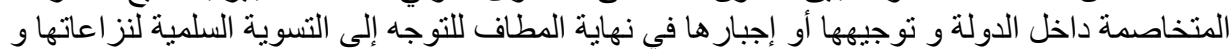

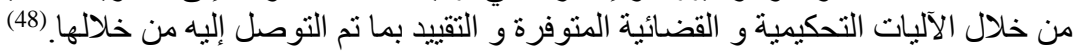

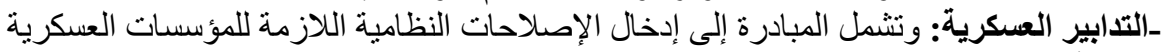

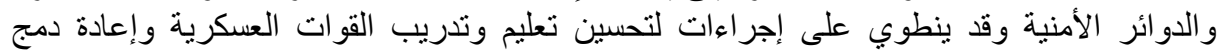

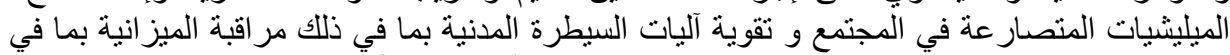

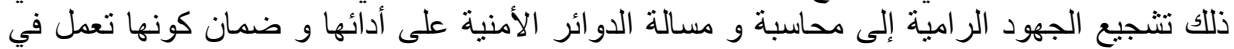

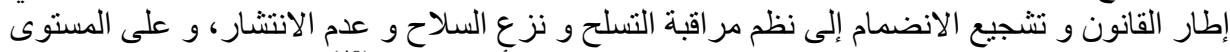

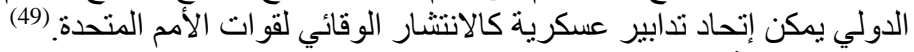

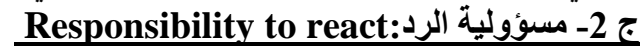

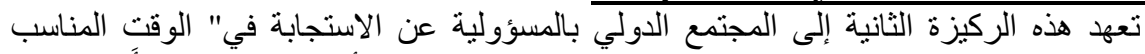

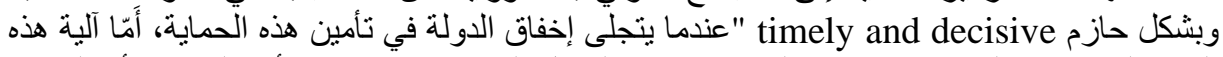

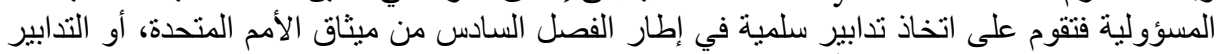

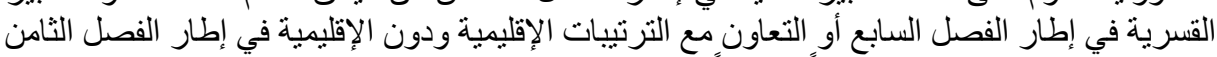

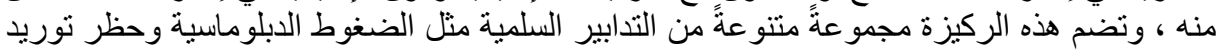

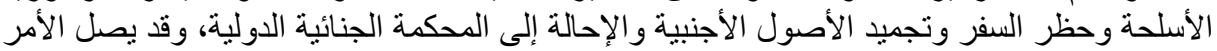

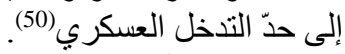

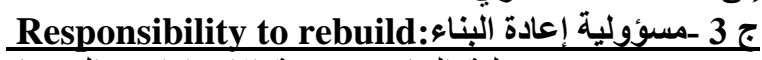

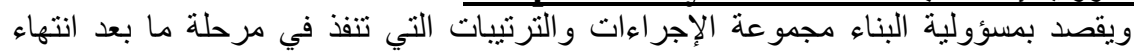

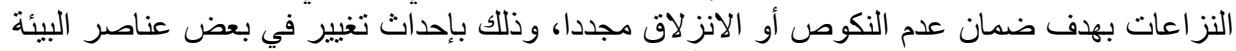

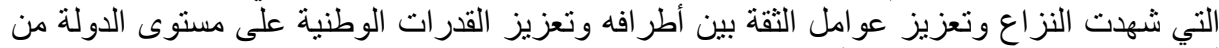
أجل إدارة نتائج النزاع ولوضئ وضع أسس التنمية (51).

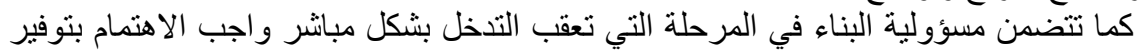

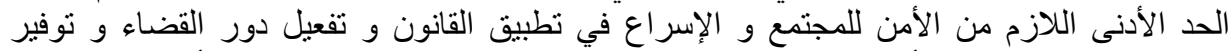

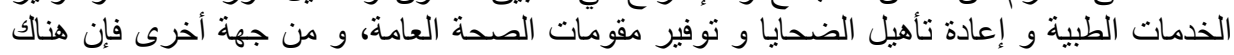

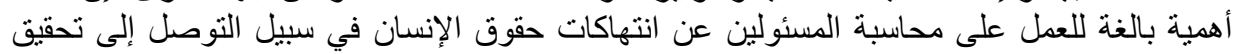

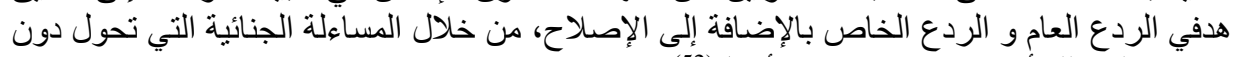
عودتهم إلى ذلك أو قيام غير هم بذات الأفعال (52).

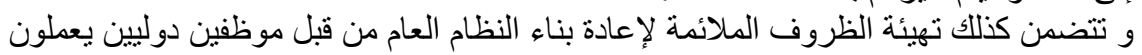

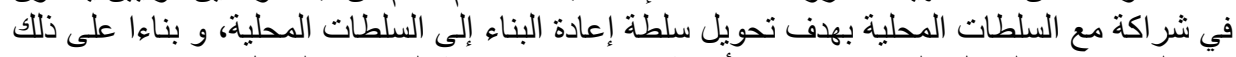

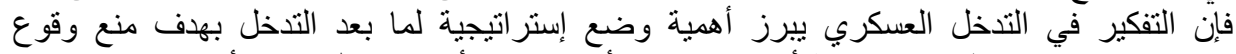

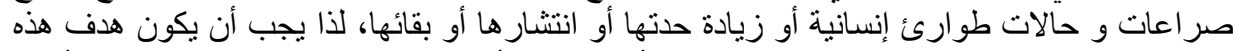

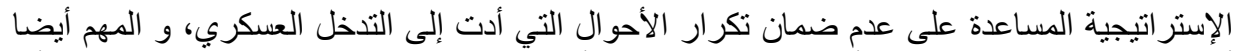

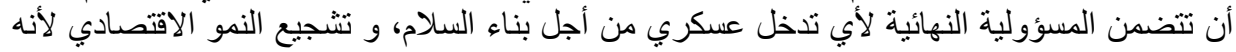

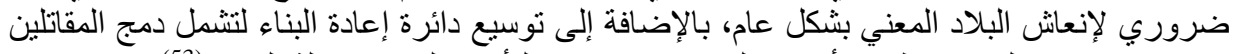
في جيش واحد و الحد من ظهور أسباب النزاع من جديد و التأكيد على بناء دولة القانون (53). 
2)-تطبيق مسؤولية الحماية على الأزمة الليبية:

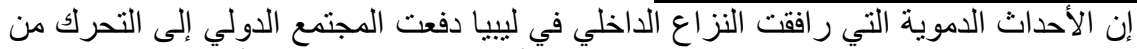

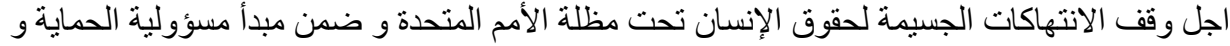
هذا ما سنتطرق إليه فيما يلي: أ خلفيات و مسار الأزمة الليبية فئية

قبل التطرق إلى تطبيق مسؤولية الحماية في الأزمة الليبية لابد من إبراز أسباب الأزمة الليبية و الإنية

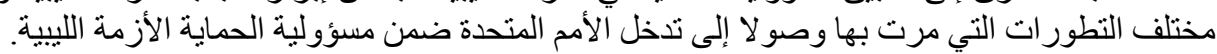

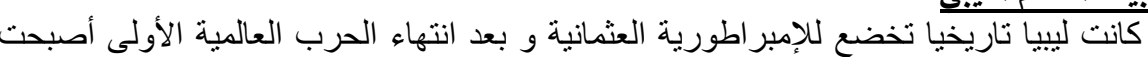

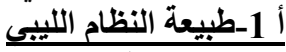

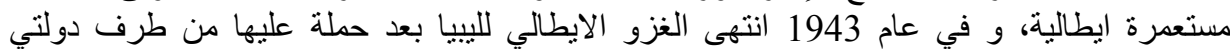

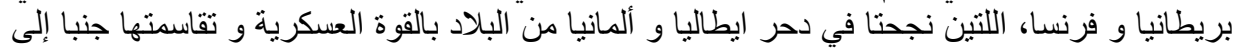

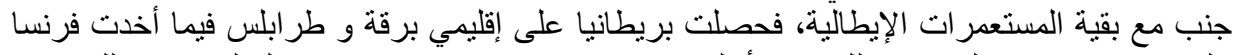

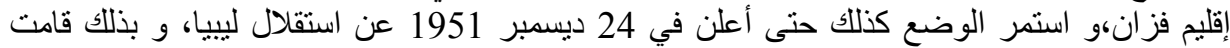

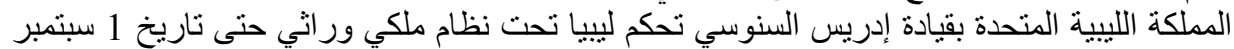

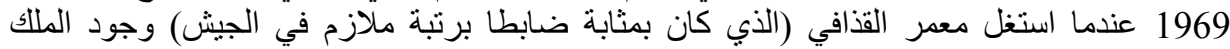

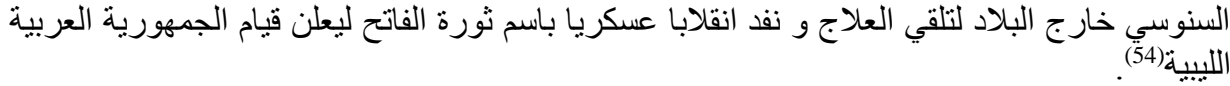

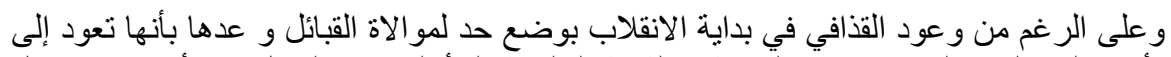

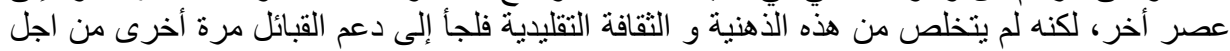

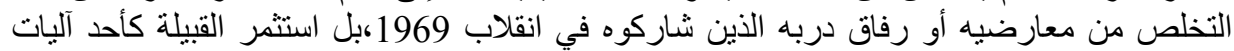

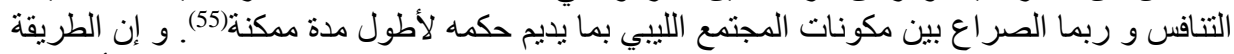

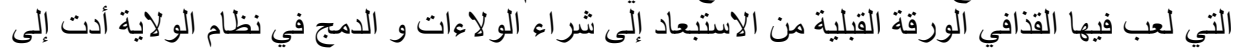

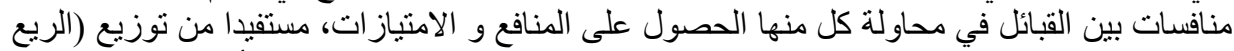

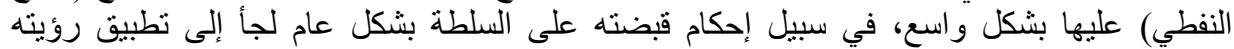

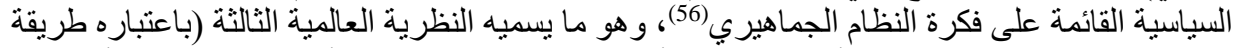
الحكم الثالثة بعد الماركسية و الرأسمالية)، ألتي ألف لها كتابا باسم الكتاب الأخضر يشرح فيها لهابة أسسهاو و

أ 2- بداية الأزمة الليبية

بدأت الاحتجاجات في 15 فيفري 2011، الإنة على اثر الاحتجاجات الثعبية ضد النظام في كل من

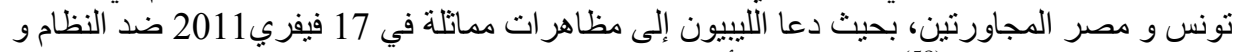

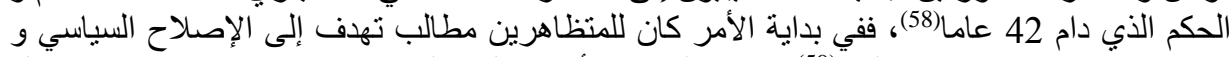

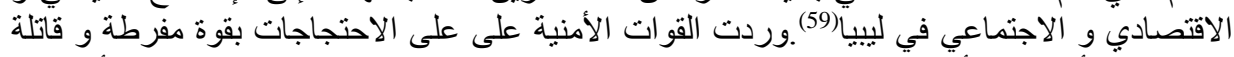

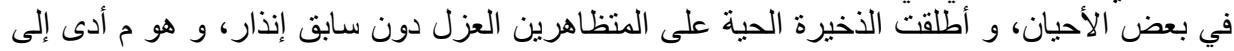

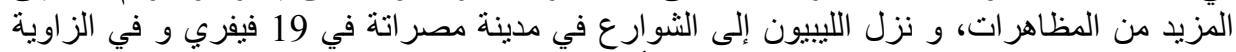

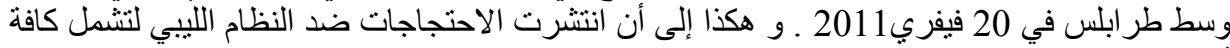

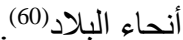

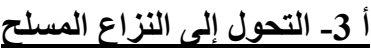

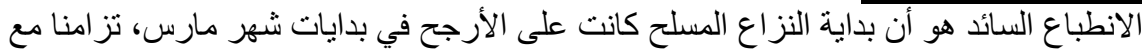

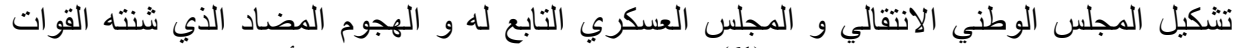

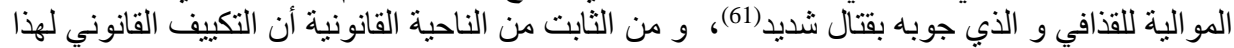

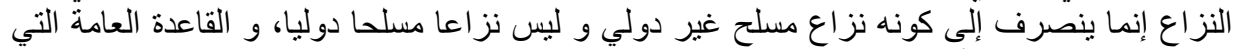
تحكم هذا النزاع تقول أن القانون الداخلي في ليبياو هو الذي دي يختص دون غيره بتسوية هذا النوع لكونه 
نزاعا داخليا، غير أنه و على سبيل الاستثناء تتولى بعض قو اعد القانون الدولي الإنساني حكم هذا النزاع اعتئ

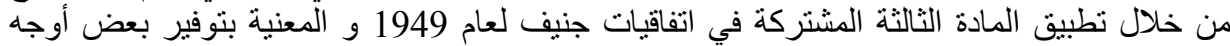

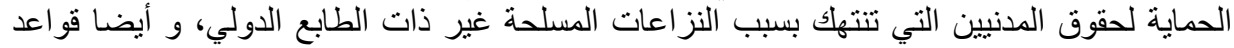

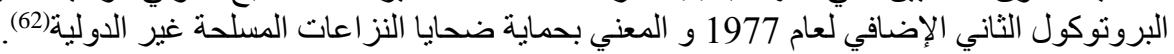

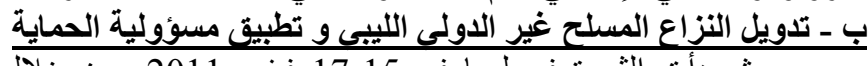

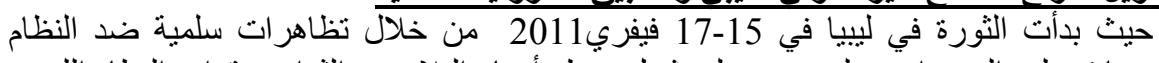

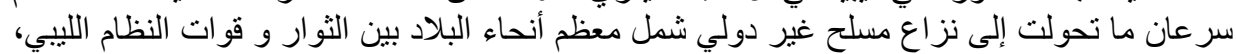

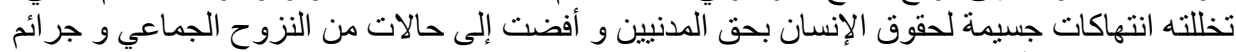

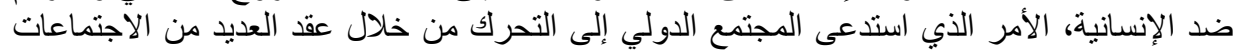

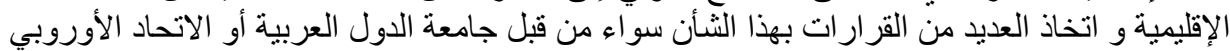

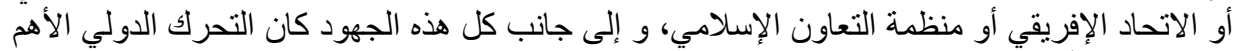

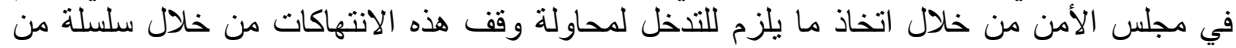

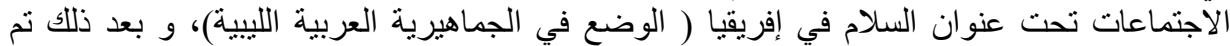

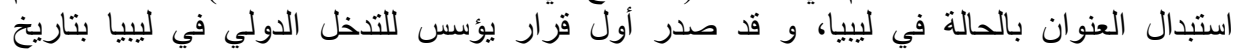

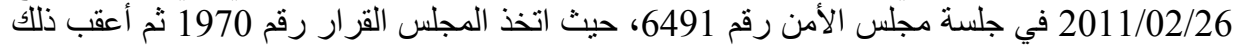

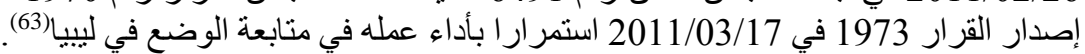

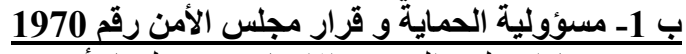

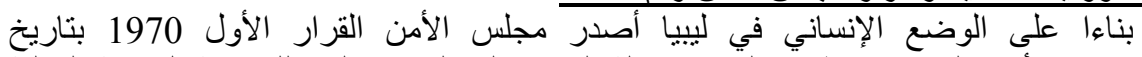

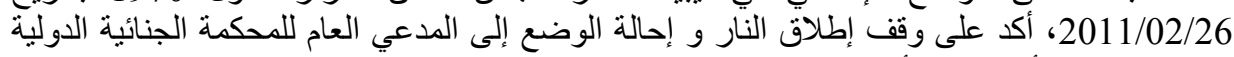

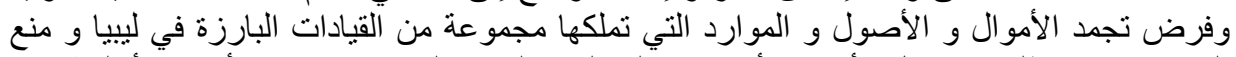

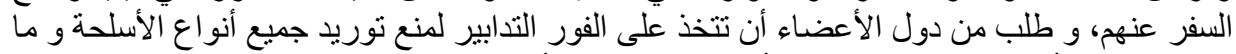

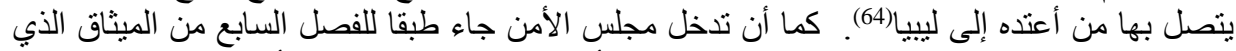

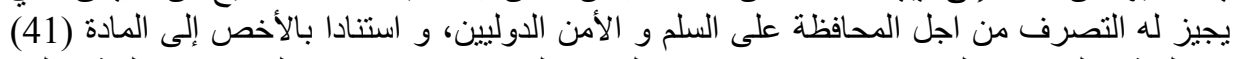

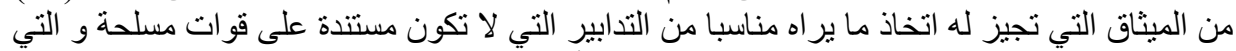
من ضمنها وقف الصلات الاقتصادية و المو اصلات بأنو اعها الدختلفة، و كذلك إمكانية قطع العلاقات

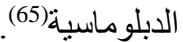

ب بـ مسؤولية الحماية و القرار رقم 1973

صدر هذا القرار في 2011/03/17 بعد زيادة حدة الانتهاكات الواسعة لحقوق الإنسان في ليبياو

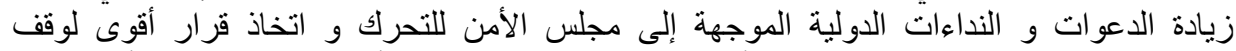

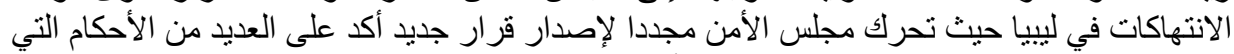

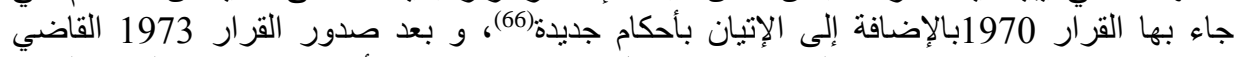

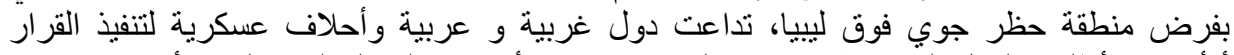

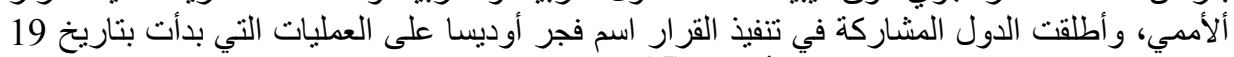

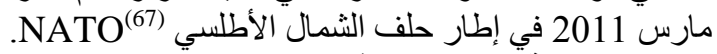
ب 3- مسؤولية إعادة البناء في ليبيا

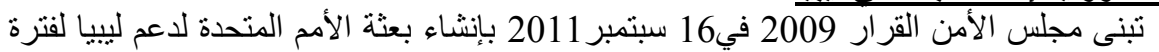

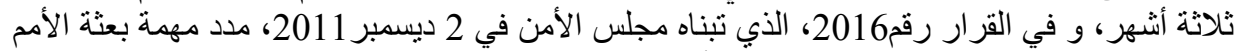

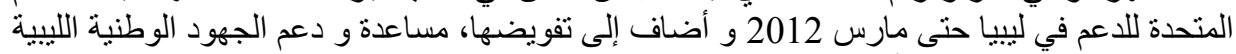

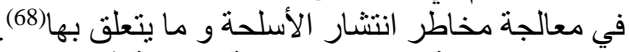
ج ـ تقييم تجربة تطبيق مسؤولية الحماية في ليييا

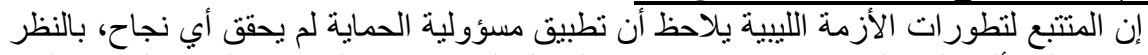

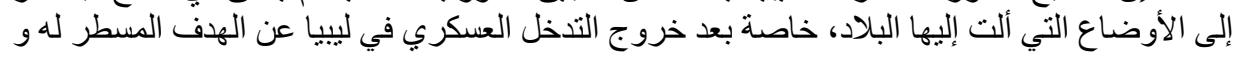


هو حماية المدنيين، إلى هدف إسقاط نظام الحكم في الدولة و هو هدف ليس لهار الئ أي صلة بمضمون

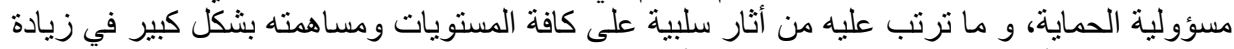

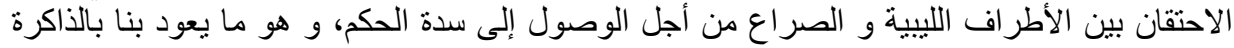
إلى تجارب التنخل الإنساني السابقة في كل من الصومال و كوسوفو و و غير ها من الحالات.

خاتمة تجان

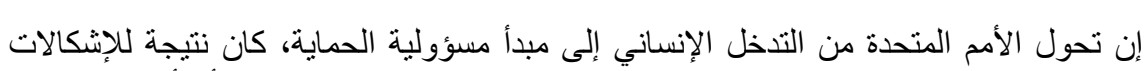

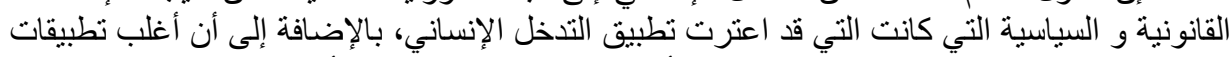

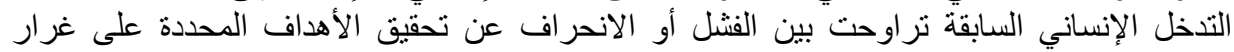

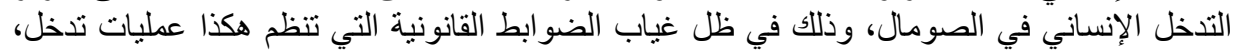

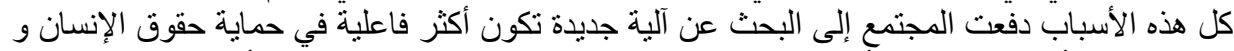

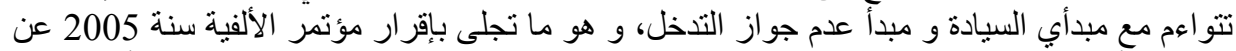

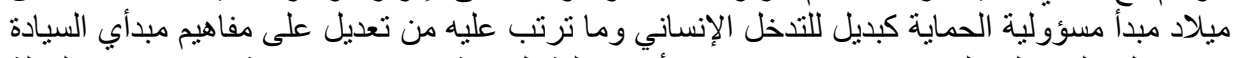

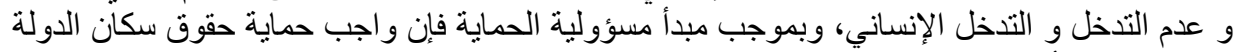

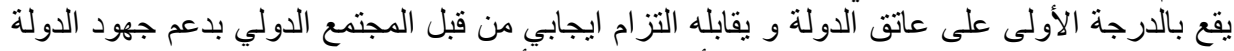

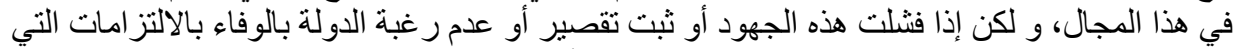

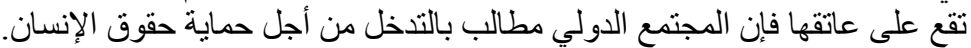

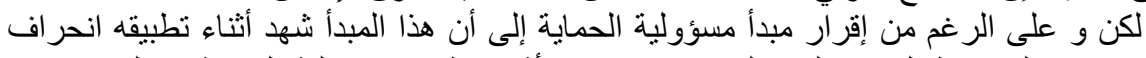

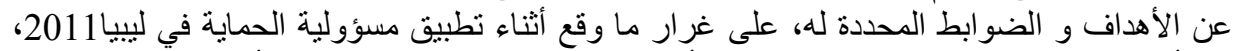

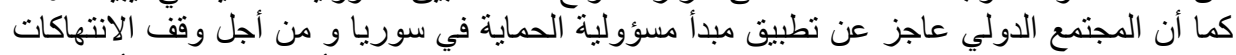

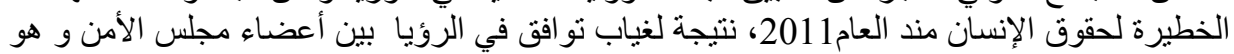

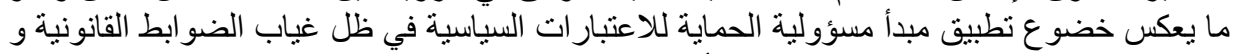
هو ما يطر ح تساؤلات حول تطبيق هذا المبدأ في المستقبل. الهو امش:

(1) محمد بوبوش ، اثر التحو لات الدولية الراهنة على مفهوم السيادة الوطنية ، تاريخ الزيارة

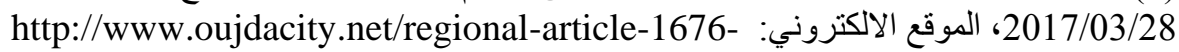
ar/regional-article-1676-ar.html (2) محمد رضا يونس عدي، التنخل و القانون الدولي العام دراسة مقارنة، المؤسسة الحديثة للكتاب،

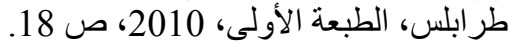
(3)عاطف علي علي الصالحي، مشروعية التدخل و القانون الدولي العام وفقا لقو اعد القانون الدولي

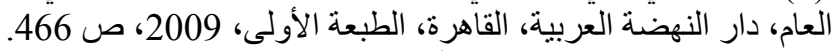

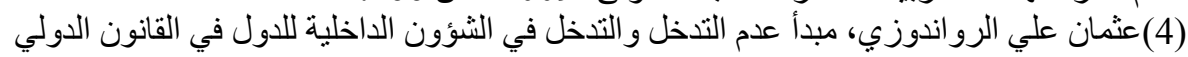

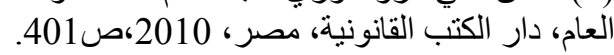

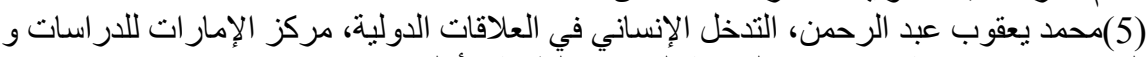

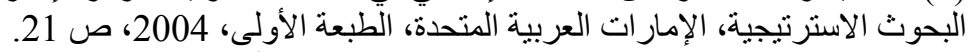

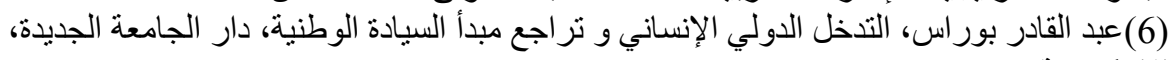

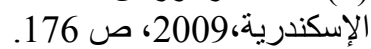
(7)مسعد قاسم عبد الرحمن، تدخل الأمم المتحدة في النزاعات المسلحة غير ذات الطابع الدولي، دار

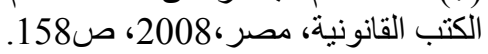

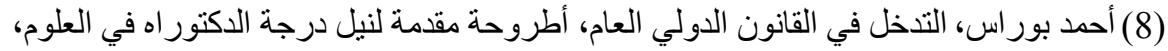

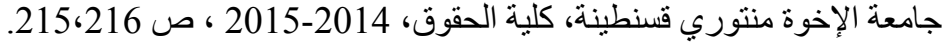
(9)عاطف علي علي الصالحي، مرجع سابق، ص صل 467. 


$$
\begin{aligned}
& \text { (10) عبد القادر بوراس، مرجع سابق، ص عابن } 178 .
\end{aligned}
$$

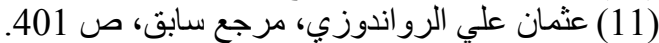

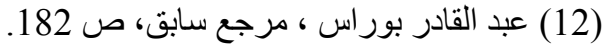

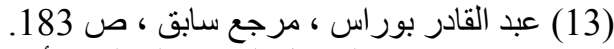

(14) فرست سوفي، الوسائل القانونية لمجلس الأمن في تدويل النزاعات النئ الداخلية و تسويتها، دراسة

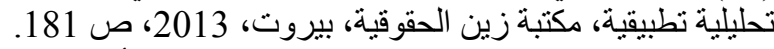

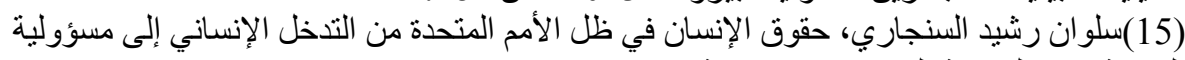

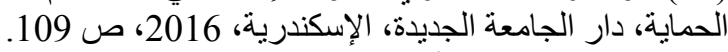

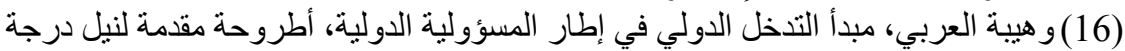

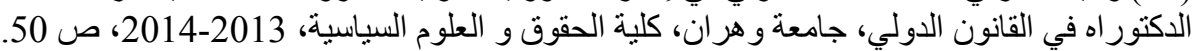

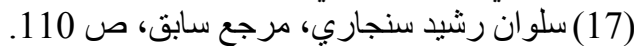

$$
\begin{aligned}
& \text { (18) عاطف علي علي الصنالحي، مرجع سابق، صناب، } 494 .
\end{aligned}
$$

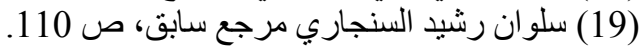

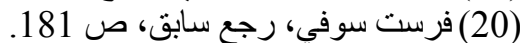

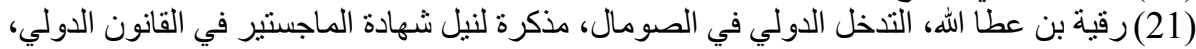

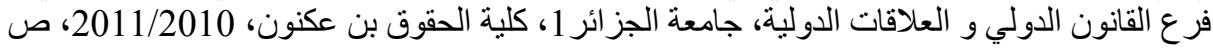

(22) المادة 2 من ميثاق الأمم المتحدة، سان فر انسيسكو، 26 جوان1945، دخل حيز النفاد 24 أكتوبر

(23)المادة 1/2 من ميثاق الأمم المتحدة و التي تتص على:" ثقوم الهيئة على مبدأ المساو اة في السادة

بين جميع أعضائها."

(24) حسين حنفي، التدخل في شؤون الدول بذريعة حماية حقوق الإنسان، دار النهضة، القاهرة،الطبعة

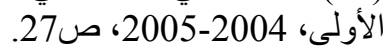

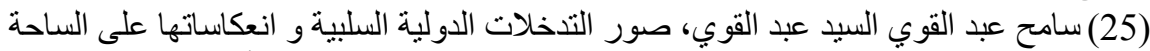

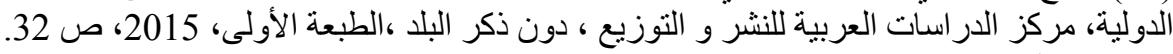

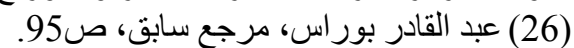

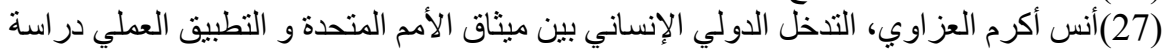

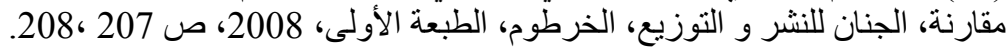

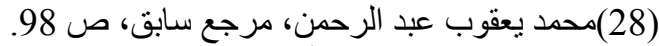

(29)معر فيصل الخولي، الأمم المتحدة و التدخل الإنساني، العربي للنشر، القاهرة، الطبعة

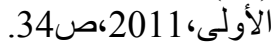

(30) حسام حسن حسان، التدخل الإنساني في القانون الدولي المعاصر، دار النهضة، القاهرة،2011، ص ص

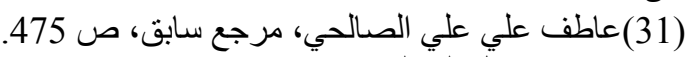

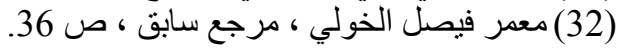

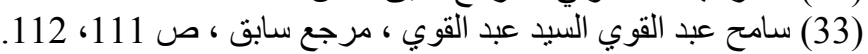

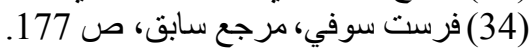

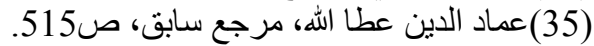

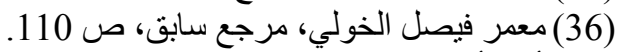

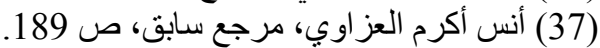

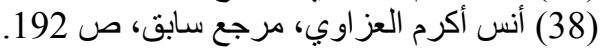


(39) Philipe alston and Euan macdonald, Humains rights intervention and use of force, oxford university press, new

York, 2009,pp 90,91.

(40)Cristina Gabriela badescu, Humanitarian intervention and the

Responsibility to protect, routledge taylor, london and new York, 2011, p02.

(41) علي بوكريطة، التدخل الدولي في إطار المسؤولية عن الحماية، مذكرة ماجستير، كلية الحقوق،

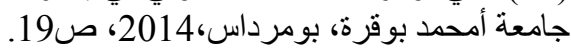

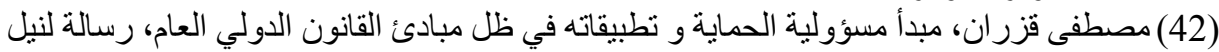

شهادة الدكتوراه في القانون العام، كلية الحقوق و العلوم السياسية ، جامعة ابي بكر بلقائيد، تلمسان،

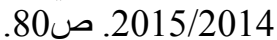

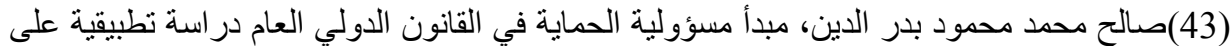

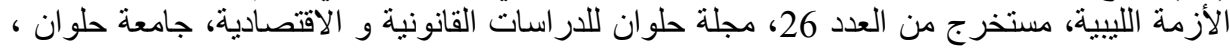

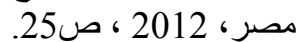

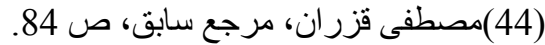

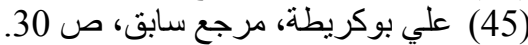

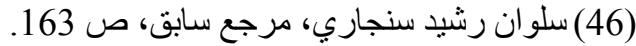

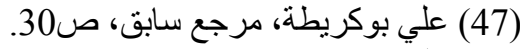

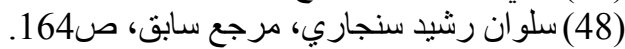

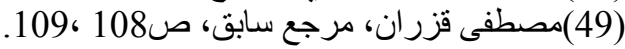

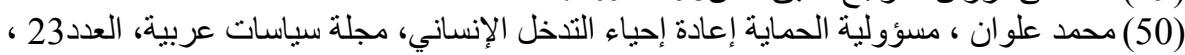

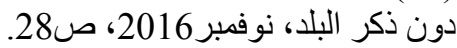

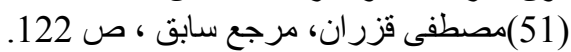

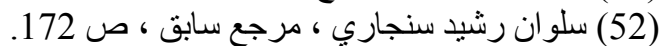

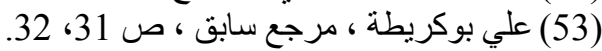

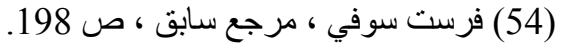

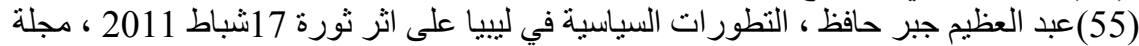

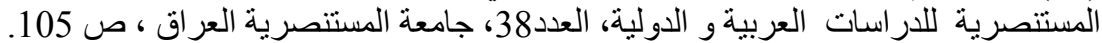

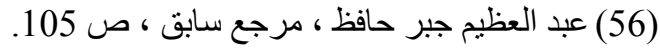

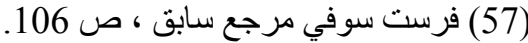

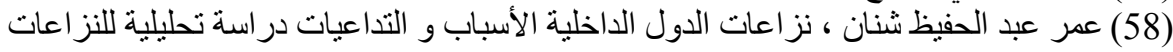

الالسلحة و غير المسلحة من منظور القانون الدولي العام و القانون الدولي الإنساني، دار الجامعة الجديدة الإيدة

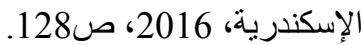

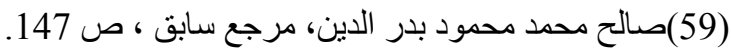

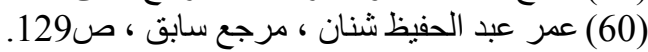

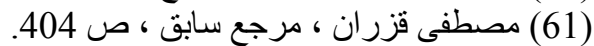

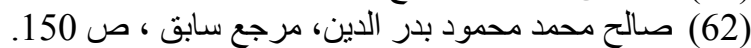

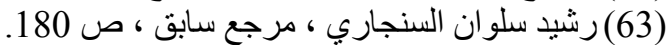

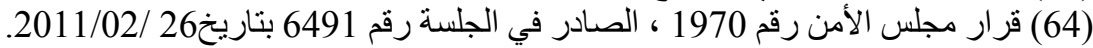

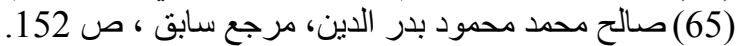

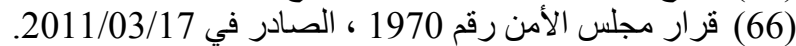

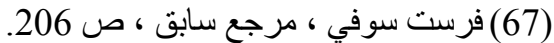

(68) عمر عبد الحفيظ شنان ، مرجع سابق ، ص ص 133. 